08

\title{
Влияние буферного слоя на формирование катализатора на основе тонкой пленки никеля для синтеза углеродных нанотрубок
}

\author{
(C) С.В. Булярский, ${ }_{1}^{1}$ Е.В. Зенова, ${ }^{1}$ А.В. Лакалин, ${ }^{1}$ М.С. Молоденский, ${ }^{1}$ А.А. Павлов, ${ }^{1}$ А.М. Тагаченков, ${ }^{1}$ \\ А.В. Терентьев ${ }^{1,2}$ \\ ${ }^{1}$ Институт нанотехнологий микроэлектроники РАН, \\ 119991 Москва, Россия \\ ${ }^{2}$ НИУ Высшая школа экономики, \\ 101000 Москва, Россия \\ e-mail: bulyar2954@mail.ru
}

(Поступило в Редакцию 1 февраля 2017 г.)

Исследованы процессы формирования наночастиц катализатора на основе тонкой пленки никеля, которая наносится на буферные слои трех видов: чистый титан, оксид титана и нитрид титана. Показано, что при проведении синтеза нанотрубки с применением трех последовательных этапов (окисления, восстановления и роста нанотрубки) может возникнуть ситуация, когда метал катализатора окажется изолирован от поверхности и соответственно от потока углеводорода, что приведет к остановке роста нанотрубок. Изоляция возникает при движении границы раздела оксида титана с газовой средой реактора, при котором оксид титана огибает наночастицу оксида никеля и изолирует ее. Получены скорость перемещения этой границы и коэффициент диффузии кислорода в оксиде титана.

DOI: $10.21883 /$ JTF.2018.12.46791.50-18

\section{Введение}

Углеродные нанотрубки (УНТ) занимают важное место в наноэлектронике [1]. Они обладают многими уникальными свойствами, среди которых свойство поглощения и испускания электромагнитного излучения. Это открывает перспективу создания приемнопередающих устройств на основе УНТ в широком диапазоне длин волн от радиочастотного до оптического [2,3]. Контакты УНТ с металлом являются выпрямляющими [4], что позволяет использовать их в качестве ректен [5]. В 1995 г. появилось несколько работ, в которых описывалось явление автоэлектронной эмиссии из УНТ [6-8]. Это явление легло в основу ряда важных направлений использования УНТ с точки зрения практики. Сказанное позволяет сделать вывод об актуальности выращивания УНТ с определенными свойствами. В последние годы для синтеза УНТ широко используется химическое парофазное осаждение (XПO, CVD) $[9,10]$. Этот метод обладает необходимой гибкостью варьирования параметров процесса, что позволяет выращивать нанотрубки различного качества.

Важной составляющей технологического процесса роста нанотрубок методом ХПО является подготовка и формирование наночастиц катализатора $[1,11]$. Рост УНТ обусловлен цепочкой процессов, которые протекают без участия и с участием катализатора. Без его участия проходят диссоциация углеводородов в газовой фазе, диффузия и осаждение молекул на поверхность металлической частицы катализатора. С участием катализатора происходит пиролиз углеводородов на его поверхности, диффузия углерода внутрь катализатора, формирование карбидов из его вещества, разложение этих карбидов на фронте кристаллизации и рост УНТ $[11,12]$. В настоящее время в технологии УНТ используются твердые тонкопленочные катализаторы $[11,13,14]$, в состав которых входит несколько тонких металлических слоев. Металлические слои при нагреве плавятся и участвуют в различных химических реакциях, которые приводят к гетерогенному составу наночастицы катализатора, из которого растет УНТ $[11,15]$. Состав и размеры наночастицы катализатора в конечном итоге приводит к определенному качеству УНТ, которая растет из данной частицы.

Формирование наночастиц катализатора из тонких пленок происходит в два этапа непосредственно перед ростом УНТ. На первом этапе образец окисляется. При окислении в сухом кислороде происходит очистка катализатора от возникших на предыдущем этапе загрязнений, кроме того, тонкие пленки металлов также частично окисляются. На втором этапе проводится восстановление в среде водорода или аммиака, восстанавливаются окисленные металлы, загрязнения поверхности катализаторов удаляются за счет образования летучих соединений с веществом газа восстановителя. Именно на этом этапе наблюдается коалесценция частиц металлов, и формируются геометрические размеры наночастиц катализатора, из которых в дальнейшем происходит рост нанотрубок. Вещества, которые составляют металлические слои, активно участвуют во взаимодействии с газовой фазой реактора, в химических реакциях окисления и восстановления, взаимно диффундируют друг в друга, а также достигают подложки и взаимодействуют с нею. Состав наночастиц изменяется. Происходит перемешивание и перемещение веществ, образующихся в катализаторе. Итогом этих процессов является обра- 
Энергия связи (пик на спектре РФС) Ni, Ti, O на поверхности образцов и соответствующее вещество, в состав которого входят элементы („ох“ - окисление, „red“ - восстановление)

\begin{tabular}{|c|c|c|c|c|}
\hline $\begin{array}{l}\text { Буферный } \\
\text { слой }\end{array}$ & Обработка & $\begin{array}{c}\mathrm{Ni}\left(2 p_{3 / 2}\right) \\
\text { энергия связи, eV }\end{array}$ & $\begin{array}{c}\mathrm{Ti}\left(2 p_{3 / 2}, 2 p_{1 / 2}\right) \\
\text { энергия связи, } \mathrm{eV}\end{array}$ & $\begin{array}{c}\mathrm{O}(1 s) \\
\text { энергия связи, } \mathrm{eV}\end{array}$ \\
\hline \multirow{2}{*}{$\mathrm{Ti}$} & ox & $\begin{array}{l}855.60 \text { (гидроксид) } \\
857.69 \text { (оксид) }\end{array}$ & $458.41,464.11\left(\mathrm{TiO}_{2}\right)$ & $\begin{array}{l}529.89 \text { (оксиды мет.) } \\
531.29 \text { (гидроксиды) } \\
532.35 \text { (органика) }\end{array}$ \\
\hline & $\begin{array}{l}\text { ox }+ \\
\text { red }\end{array}$ & не детектируется & $\begin{array}{l}\text { 454.82, } 460.62(\mathrm{TiN}) \\
455.88,461.28\left(\mathrm{TiO}_{x} \mathrm{~N}_{y}\right) \\
\text { 458.16, } 463.86\left(\mathrm{TiO}_{2}\right.\end{array}$ & $\begin{array}{l}530.21 \text { (оксиды мет.) } \\
531.74 \text { (гидроксиды) } \\
533.09 \text { (органика) }\end{array}$ \\
\hline \multirow[b]{2}{*}{$\mathrm{TiO}_{2}$} & ox & $\begin{array}{l}854.64(\mathrm{NiO}) \\
856.41,857.34\left(\mathrm{Ni}_{2} \mathrm{O}_{3}\right)\end{array}$ & $458.63,464.33\left(\mathrm{TiO}_{2}\right)$ & $\begin{array}{l}529.35 \text { (оксиды мет.) } \\
532.20 \text { (С-О) }\end{array}$ \\
\hline & $\begin{array}{l}\text { ox }+ \\
\text { red }\end{array}$ & $\begin{array}{l}852.17 \text { (мет.) } \\
854.04 \text { (NiO) } \\
855.85 \text { (гидроксиды) } \\
857.30\left(\mathrm{Ni}_{2} \mathrm{O}_{3}\right)\end{array}$ & $\begin{array}{l}455.30(\mathrm{TiO}) \\
456.87,462.78\left(\mathrm{TiO}_{x} \mathrm{~N}_{y}\right) \\
458.35,464.19\left(\mathrm{TiO}_{2}\right) \\
460.65(\mathrm{TiN})\end{array}$ & $\begin{array}{l}529.63 \text { (оксиды мет.) } \\
531.14(\mathrm{C}=\mathrm{O}) \\
532.19(\mathrm{C}-\mathrm{O})\end{array}$ \\
\hline \multirow[b]{2}{*}{ TiN } & ox & $\begin{array}{l}853.89(\mathrm{NiO}) \\
855.60,856.88\left(\mathrm{Ni}_{2} \mathrm{O}_{3}\right)\end{array}$ & $458.15,463.87\left(\mathrm{TiO}_{2}\right)$ & $\begin{array}{l}529.29 \text { (оксиды мет.) } \\
531.18(\mathrm{C}=\mathrm{O}) \\
532.85(\mathrm{C}-\mathrm{O})\end{array}$ \\
\hline & $\begin{array}{l}\text { ox }+ \\
\text { red }\end{array}$ & $\begin{array}{l}852.34 \text { (мет.) } \\
854.07 \text { (NiO) } \\
855.95 \text { (гидроксиды) } \\
857.61\left(\mathrm{Ni}_{2} \mathrm{O}_{3}\right)\end{array}$ & $\begin{array}{l}455.05(\mathrm{TiO}) \\
456.64,462.04\left(\mathrm{TiO}_{x} \mathrm{~N}_{y}\right) \\
458.45,464.15\left(\mathrm{TiO}_{2}\right) \\
460.45(\mathrm{TiN})\end{array}$ & $\begin{array}{l}529.77 \text { (оксиды мет.) } \\
531.08(\mathrm{C}=\mathrm{O}) \\
532.11(\mathrm{C}-\mathrm{O})\end{array}$ \\
\hline
\end{tabular}

зование гетерогенных частиц катализатора, из которых происходит рост УНТ.

Настоящая работа изучает процессы окисления и восстановления катализатора, состоящего из тонкой пленки никеля, напыленной на буферный слой, в качестве которого использовался титан, оксид титана и нитрид титана. Исследуются особенности свойств наночастиц катализатора, которые возникают при этом, а также качество углеродных нанотрубок, которые растут с участием этих частиц.

\section{Экспериментальные результаты}

Катализатор, который исследуется в настоящей работе, состоит из тонкой пленки никеля толщиной $2-4 \mathrm{~nm}$, которая магнетронным методом напыляется на буферный слой. Этот слой формируется на подложке кремния, покрытого оксидом $\mathrm{SiO}_{2}$. В работе изучается процесс взаимодействия никеля и буферных слоев трех типов с газовой фазой реактора. Первый тип образцов содержал буферный слой, состоящий из чистого титана, второй из оксида титана $\left(\mathrm{TiO}_{2}\right)$, а третий — из нитрида титана (TiN). Bсе три типа образцов проходили все этапы технологии синтеза УНТ. Первый этап заключался в окислении в чистом кислороде при температуре $280^{\circ} \mathrm{C}$ в течение $5 \mathrm{~min}$, второй - в восстановлении в потоке аммиака при температуре $680^{\circ} \mathrm{C}$ в течение $5 \mathrm{~min}$, третья заключительная стадия представляла рост УНТ при температуре восстановления катализатора из потока газовой смеси состава $\mathrm{C}_{2} \mathrm{H}_{2}: \mathrm{NH}_{3}: \mathrm{Ar}$ в соотношении потоков газов $1: 1: 1$ при расходе $100 \mathrm{~cm}^{3} / \mathrm{min}$. До начала термообработок и после каждой стадии синтеза проводилось исследование морфологии, химического состава катализатора и распределения элементов по глубине рабочего слоя.

Морфология исследовалась с помощью растрового электронного микроскопа. Распределение химического состава слоя катализатора как на его поверхности, так и по глубине определялось методом рентгеновской фотоэлектронной спектроскопии (РФС) с помощью универсального микроанализатора VersaProbIII. Для каждой группы образцов измерялись спектры РФС на поверхности и по объему (при послойном стравливании), рассчитывалась атомная концентрация элементов (в \%) от времени травления. В каждой группе такие исследования проводились на образцах до начала окисления, после окисления, после восстановления. Полученные экспериментальные данные обрабатывались программным обеспечением микроанализатора VersaProbIII. В таблице представлены результаты анализа поверхностных спектров РФС для элементов $\mathrm{Ti}, \mathrm{Ni}, \mathrm{O}$. Для каждого пика указано вещество, в состав которого входит данный элемент.

На рис. 1 приведены спектры РФС титана, никеля и кислорода на поверхности образцов первой группы. После окисления образцов первой группы, в которых пленка никеля наносилась на чистый титан, пики РФС, соответствующие металлическим состояниям никеля и 

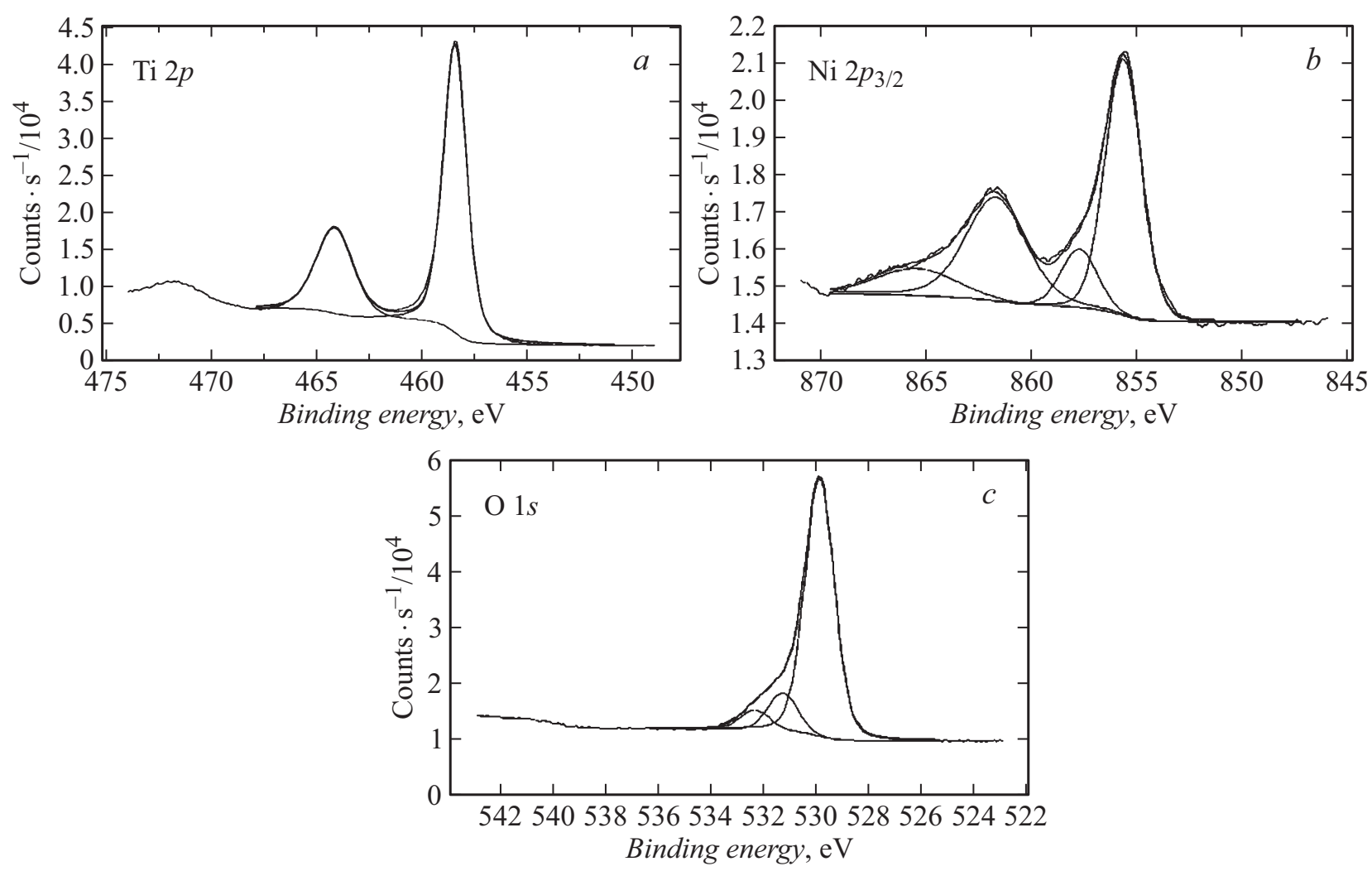

Рис. 1. Спектры РФС титана $(a)$, никеля $(b)$ и кислорода $(c)$ на поверхности образца первой группы после окисления.

титана на поверхности, исчезают (рис. $1, a, b$, таблица). Таким образом, поверхность катализатора окисляется полностью. Титан находится в виде оксида $\mathrm{TiO}_{2}$, (пики 458.41 и $464.11 \mathrm{eV})$, а никель - в формах оксида и гидроксида (пики 857.69 и $855.60 \mathrm{eV}$ ). Восстановление в аммиаке не приводит к появлению на поверхности образца металлических наночастиц (см. таблицу).

Судя по результатам анализа, титан участвует в многочисленных химических реакциях, которые приводят к появлению нитрида и оксида титана (пики 454.82, 458.16, $460.62,463.86 \mathrm{eV})$, а также твердых растворов этих соединений различного состава (пики 455.88, $461.28 \mathrm{eV}$ ). Еще раз подчеркнем, что никеля в металлическом виде на поверхности нет (см. таблицу), рост УНТ не происходит. Сказанное подтверждается анализом состояний кислорода (рис. $1, c)$, который показывает, что кислород реагирует с металлами (титаном и никелем) в процессе окисления, образуя оксиды, при этом энергия связи, определяющая максимум пика РФС, составляет $529.89 \mathrm{eV}$ (см. рис. 1, c). Кислород также образует гидроксиды (пик $531.29 \mathrm{eV}$ ) и входит в состав органических соединений (пик $532.35 \mathrm{eV}$ ). Азот входит в остатки органических соединений (пик $399.94 \mathrm{eV}$ ). После восстановления кислород продолжает оставаться в оксидах (пик $530.21 \mathrm{eV}$ ), гидроксидах (пик $531.74 \mathrm{eV}$ ) и органических соединениях (пик $533.09 \mathrm{eV}$ ) (см. таблицу).

Исследование образцов при послойном стравливании пленки катализатора после первых двух стадий (окисле- ния и восстановления) показало, что в глубине образца металлический никель есть (рис. 2,a). Никель частично диффундирует к границе раздела титана с окислом кремния, а в приповерхностном слое его металлические наночастицы скрыты оксидами и оксинитридами титана, которые изолируют его от потока атомов углерода при синтезе. Рост нанотрубок в этом случае не наблюдается.

Исследование образцов второй группы, в которых никель наносился на оксид титана $\mathrm{TiO}_{2}$, показало, что никель на поверхности в результате первой стадии обработки окисляется частично до стабильного оксида $\mathrm{NiO}$ и частично до нестабильного $\mathrm{Ni}_{2} \mathrm{O}_{3}$. Металлических частиц никеля на поверхности не остается. Однако после восстановления металлические наночастицы никеля образуются вновь (см. рис. 2, $b$ ). Эти частицы выполняют свою функцию катализатора и рост УНТ происходит. Титан претерпевает те же превращения, что и в предыдущем случае. Исследование образцов третьей группы, буферный слой которых был выполнен из нитрида титана, аналогично предыдущему случаю.

Измерение спектров РФС с последовательным стравливанием слоя катализатора позволяет получить распределение элементов по глубине образцов (рис. 3), а также судить о распределении соединений металлов с кислородом и азотом. Результаты анализа на образцах первой группы показывают, что сразу после напыления (см. рис. 3, а) никель, хотя и несколько окисленный, располагается в поверхностном слое образцов. После 


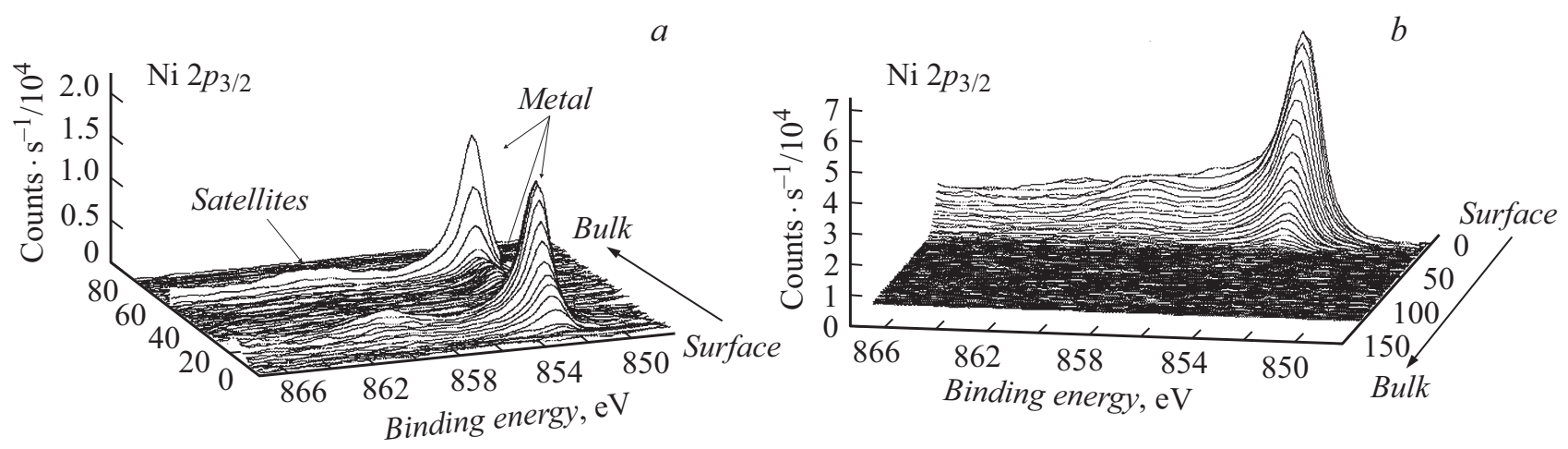

Рис. 2. Распределение никеля по объему после операции окисления и восстановления в образцах первой $(a)$ и второй $(b)$ групп.

окисления (см. рис. 3,b) он оказывается под поверхностью, которая преимущественно состоит из оксида титана или твердых растворов оксида и нитрида титана. Следующий этап (обработка в восстановительной среде) не приводит к восстановлению металлического никеля на поверхности (см. рис. 3,c). Кроме того, никель в образцах первой группы диффундирует сквозь слой титана к границе с оксидом кремния. Титан участвует в многочисленных реакциях, формируя оксиды и нитриды. Он также взаимодействует с оксидом кремния, образуя силициды. В образцах второй и третьей групп оксид и нитрид титана являются препятствием для диффузии никеля. По этой причине никель остается в приповерхностном слое и после восстановления находится в металлическом и частично окисленном состоянии. Это позволяет ему участвовать в процессе каталитического распада углеводородов и обеспечивать рост нанотрубок.

\section{Обсуждение полученных результатов}

Экспериментальные результаты показали, что главным препятствием для роста УНТ является изоляция никеля от поверхности соединениями титана. В результате газ-восстановитель и углеводород не могут проникнуть к никелю. Его оксиды не восстанавливаются и роста УНТ не происходит.

Исследуем причину, по которой никель оказывается под слоем соединений титана в первом типе образцов и почему это не происходит для образцов второго и третьего типа. Очевидно, что она скрывается в поведении титана при окислении.

Модель окисления материала при диффузии кислорода через слой растущего окисла была разработана при изучении процесса термического окисления кремния. Это широко известная модель Дила и Гроува [16,17], которая и по сей день используется в микроэлектронной технологии для описания роста диэлектрических слоев $\mathrm{SiO}_{2}$.

Модель Дила-Гроува основана на рассмотрении стационарных потоков кислорода через границу газ- $\mathrm{SiO}_{2}$, в слое $\mathrm{SiO}_{2}$ и через границу $\mathrm{SiO}_{2}-\mathrm{Si}$. Она имеет ограничения: во-первых, аналитические выражения для зависимости толщины окисла $\mathrm{SiO}_{2}$ от времени окисления получены только для двух предельных случаев, во-вторых, эта модель не может применяться в случае очень тонких пленок $\mathrm{SiO}_{2}$. В дальнейшем модель Дила-Гроува была пересмотрена и исправлены некоторые неточности. Сама проблема окисления Ті возникла в связи с применением этого материала в различных компонентах, подвергающихся воздействию влажности, высоких температур, химически активных веществ. В [18] представлено теоретическое описание окисления титана с акцентом на математический вывод двумерной $(2 D)$ модели и ее аналитическое решение для некоторых особых случаев. Эта модель учитывает неподвижный кислород, содержащийся в оксиде, скачок концентрации кислорода, содержащегося в оксиде, и кислорода, растворенного в Тi, но она не учитывает объемное расширение $\mathrm{TiO}_{2}$. Это является большим недостатком, так, объем элементарной ячейки оксида титана больше, чем объем ячейки чистого титана более, чем в 10 раз. Это связано с тем, что отношение Пиллинга-Бедворта в Ті больше единицы. Этот недостаток устранен в работе [19], в которой разработана $3 D$-модель окисления титана на основе диффузии кислорода в оксиде, получены уравнения, описывающие движение границ кислород-оксид и металл-оксид, связанных с расширением оксида. На данный момент это одна из полных моделей окисления Ті. Аналитические выражения этой работы, полученные для случая одномерного плоского окисления, можно использовать для оценки коэффициента диффузии кислорода в диоксиде титана. Из данной модели вытекает, что при окислении происходит расширение окисленной части катализатора, и граница поверхности движется на встречу диффузионному потоку кислорода в титан. При этом никель участвует в двух процессах: во-первых, диффундирует сквозь слой титана, о чем свидетельствует накопление никеля на границе с оксидом кремния, во-вторых, он окисляется. Оксид никеля является устойчивым соединением. Поэтому диффундировать он может только в качестве молекулы, коэффициент диффузии которой 

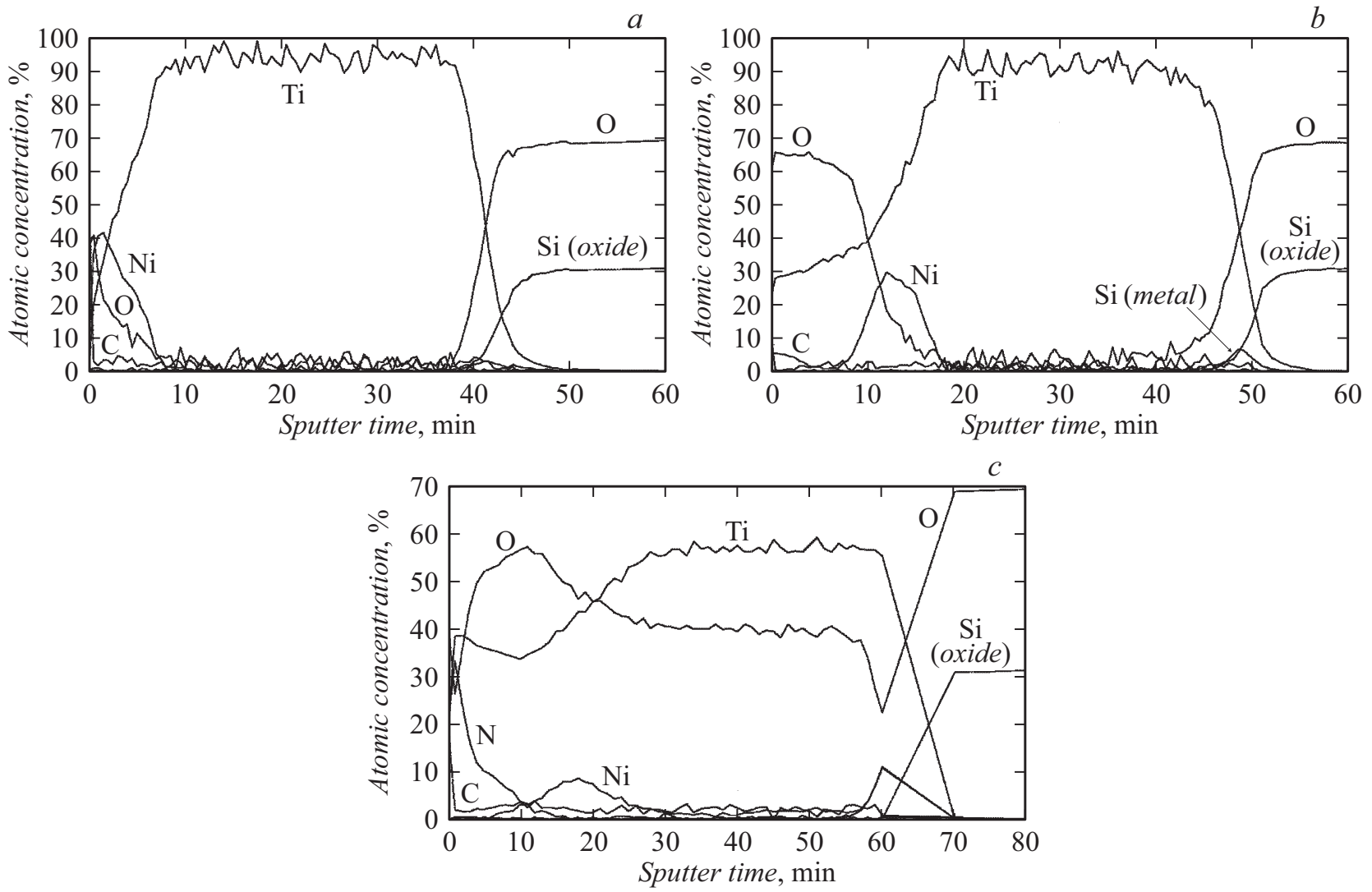

Pис. 3. Распределение веществ в образцах первой группы сразу после напыления $(a)$, после окисления $(b)$, после окисления и восстановления $(c)$.

значительно меньше, чем у атомов никеля. В связи с этим после того как никель окислился до оксида, он диффундировать не может и остается у границы с титаном. Титан же, окисляясь, огибает оксид никеля и его слой, что приводит к изоляции оксида от воздействия газов реактора. Поэтому никель на дальнейших этапах не восстанавливается и не участвует в росте УНТ. Для того чтобы подтвердить эти модели, проведем оценку коэффициента диффузии кислорода в титане и скорость перемещения границы титана с газами, находящимися в реакторе.

Эксперимент по окислению титана проводился на двух одинаковых пластинах в одном процессе. После окисления первая пластина изымалась из дальнейших технологических операций, а на второй пластине проводилось восстановление катализатора. После этого обе пластины исследовались методом РФС. Операции окисления и восстановления позволяют сделать приближенную оценку коэффициента диффузии кислорода в оксиде титана при соответствующих температурах.

Модель окисления представим следующим образом. Кислород при температуре окисления, соприкасаясь с титаном, сразу его окисляет. Дальнейшее окисление титана возможно, только если кислород достигнет границы чистого металла с его оксидом, диффундируя при этом сквозь этот оксид. Таким образом, диффузия кислорода при окислении титана всегда происходит через $\mathrm{TiO}_{2}$. На рис. 3, $a$ представлены распределение концентрации элементов (в процентах) от времени ионного травления. Для того чтобы пересчитать распределения по глубине, проводилась оценка скорости травления в РФС установке на образцах первого типа, т. е. сразу после напыления. Она составляла $1.2 \mathrm{~nm} / \mathrm{min}$. В дальнейшем эта величина считалась неизменной. На рис. $3, b$ показаны атомные концентрации элементов (в \%) этого же образца после окисления в атмосфере кислорода в течение $t=5 \mathrm{~min}$ при температуре $T=280^{\circ} \mathrm{C}$. Толщину слоя $\mathrm{TiO}_{2}$ можно оценить по положению точки, в которой пересекаются кривые атомных концентраций кислорода и титана. Для этой точки время травления составляет примерно $11 \mathrm{~min}$. Зная скорость и время травления, была оценена толщина слоя $\mathrm{TiO}_{2}: x_{1}=13.2 \mathrm{~nm}$. Кроме того, отношение $N_{1} / N_{0}$ в этой точке равно $N_{1} / N_{0}=39 / 66=0.59$, а время диффузии составляет $t=300 \mathrm{~s}$. Полученные значения позволяют оценить скорость перемещения границы $\mathrm{TiO}_{2}$ - газ, равную $0.044 \mathrm{~nm} / \mathrm{s}$. Заметим также, что величина перемещения границы поверхности существенно больше размеров наночастиц оксида титана, которые, как было упомянуто, закрепляются на границе раздела $\mathrm{TiO}_{2}-\mathrm{Ti}$. Поэтому и происходит изоляция оксида никеля от поверхности. Предполагая, что диффузия кислорода в оксиде титана протекает по закону диффузии 
из неограниченного источника $N=N_{0} \operatorname{erfc}\left(\frac{x}{2 \sqrt{D t}}\right)$, вычисляем коэффициент диффузии для температуры $280^{\circ} \mathrm{C}: D \approx 1.0 \cdot 10^{-14} \mathrm{~cm}^{2} / \mathrm{s}$.

На рис. 3, $c$ представлены распределения веществ после двух последовательных операций: окисления в атмосфере кислорода $\left(5 \mathrm{~min}, 280^{\circ} \mathrm{C}\right)$ и восстановления в атмосфере аммиака $\left(5 \mathrm{~min}, 680^{\circ} \mathrm{C}\right)$. Предполагается, что после окисления вторая пластина имела такое же распределение атомов, как и первая, аналогично рис. $3, b$. Операция восстановления позволяет оценить значение коэффициента диффузии кислорода в оксиде титана при температуре $T=680^{\circ} \mathrm{C}$. При операции восстановления происходит диффузия кислорода, накопленного при операции окисления в слое оксида титана, оценка толщины которого была сделана выше. Поэтому предполагаем, что диффузия протекает по закону диффузии из слоя конечной толщины $N=N_{1}\left(\operatorname{erfc}\left(\frac{d-x}{2 \sqrt{D t}}\right)+\left(\frac{d+x}{2 \sqrt{D t}}\right)\right)$, где $d=x_{1}$. Из рис. 3, $c$ для времени травления $60 \mathrm{~min}$ находим толщину всего слоя, содержащего кислород: $x_{2}=72 \mathrm{~nm}$. Отношение $N_{2} / N_{1}$ в этой точке равно $N_{2} / N_{1}=24 / 57=0.421$. Для времени диффузии $t=300 \mathrm{~s}$ и начальной толщины $d=x_{1}$ находим значение коэффициента диффузии для температуры $680^{\circ} \mathrm{C}: D \approx 8.4 \cdot 10^{-14} \mathrm{~cm}^{2} / \mathrm{s}$. Эти величины в определенной степени согласуются с результатами работ $[19,20]$. Существующее различие может быть обусловлено тем, что в указанных работах эксперименты проводились на массивных образцах, а в нашем случае это проводится на слоях наноразмерной толщины.

Буферный слой оксида титана стабилен к процессу окисления и поверхность в этом случае не перемещается. То же самое можно сказать о нитриде титана, который частично окисляется до оксинитридов, но исследование распределения веществ, составляющих каталитический слой, по глубине показало, что это не оказывает существенного влияния на положение никеля относительно поверхности. Поэтому оксид никеля восстанавливается и на нем возможен рост УНТ. Буферный слой нитрида титана является более предпочтительным в том случае, когда важна вертикальная проводимость между трубками и подложкой. В этом случае вместо оксида кремния можно сразу на поверхности кремния создавать слой нитрида титана.

\section{Заключение}

Разработка технологии выращивания УНТ методом ХПО с использованием тонкопленочных катализаторов требует тщательного изучения физико-химических процессов, которые сопровождают формирование наночастицы катализатора. Частица, которая образовалась при термических обработках в различных газовых средах, является гетерогенной и может кроме металла катализатора включать его оксиды и другие соединения, которые могут возникнуть в процессе ее формирования. Рост нанотрубки происходит только при участии металла катализатора, поэтому его количество в наночастице должно быть максимально. Кроме того, к этой частице необходим свободный доступ углеводородов. В настоящей работе показано, что необходимого качества наночастицы катализатора можно достичь выбором буферного слоя между пленкой катализатора и подложкой, а также выбором температуры и времени процессов окисления и восстановления.

Авторы выражают благодарность и признательность John Newman, Director of Marketing at PHI за техническую и методическую помощь в проведении исследований на сканирующем рентгеновском фотоэлектронном спектрометре PHI VersaProbIII.

\section{Список литературы}

[1] Булярский C.B. Углеродные нанотрубки: технология, управление свойствами, применение. Ульяновск: Стрежень, 2011. 432 с.

[2] Rutherglen C., Burke P. // Nano Lett. 2007. Vol. 7. N 11. P. 3296-3299. DOI: $10.1021 / \mathrm{n} 10714839$

[3] Jensen K., Weldon J., Garcia H., Zettl A. // Nano Lett. 2007. Vol. 7. N 11. P. $3508-3511$. DOI: $10.1021 / \mathrm{n} 10721113$

[4] Булярский С.В., Булярская С. А., Вострещова Л.Н., Дудин А.А., Орлов А.П., Павлов А.А., Басаев А.С., Кицюк Е.П., Шаманаев А.А., Шаман Ю.П. // Нано- и микросистемная техника. 2015. № 5 (158). С. 3-8.

[5] Kempa K., Rybczynski J., Huang Z.P., Gregorczyk K. et al. // Adv. Mater. 2007. Vol. 19 N 3. P. 421-426. DOI: $10.1002 /$ adma.200601187

[6] Chernozatonskii L.A., Gulyaev Y.V., Kosakovskaja Z.J. et al. // Chem. Phys. Lett. 1995. Vol. 233. P. 63-68. DOI: 10.1016/0009-2614(94)01418-U

[7] DeHeer W.A., Chatelain A., Ugarte D. // Science. 1995. Vol. 270. P. 1179-1180. DOI: 10.1126/science.270.5239.1179

[8] Rinzler A.G., Hafner J.H., Nikolaev P. et al. // Science. 1995. Vol. 269. P. 1550-1553. DOI: 10.1126/science.269.5230.1550

[9] Louchev O.A., Laude Th., Sato Y., Kanda H. // J. Chem. Phys. 2003. Vol. 118. N 16. P. 7622-7634. DOI: $10.1063 / 1.1562195$

[10] Jourdain V., Bichara Ch. // Carbon. 2013. Vol. 58. P. 2-39. DOI: 10.1016/j.carbon.2013.02.046

[11] Булярский C.В., Басаев А.С. Катализаторы роста углеродных нанотрубок. LAP LAMBERT Academic Publishing, 2015. $117 \mathrm{c}$.

[12] Amelinckx S., Bernaerts D., Zhang X.B., Van Tendeloo G., Van Landuyt J. // Science. 1995. Vol. 267. P. 1334-1338. DOI: $10.1126 /$ science.267.5202.1334

[13] Chhowalla M., Teo K.B.K., Ducati C., Rupesinghe N.L., Amaratunga G.A.J., Ferrari A.C., Roy D., Robertson J., Milne W.I. // J. Appl. Phys. 2001. Vol. 90. P. 5308-5317. DOI: $10.1063 / 1.1410322$

[14] Valentini L., Kenny J.M., Lozzi L., Santucci S. // J. Appl. Phys. 2002. Vol. 92. P. 6188-6194. DOI: $10.1063 / 1.1410322$

[15] Ren Z.F., Huang Z.P., Wang D.Z., Wen J.G., Xu J.W., Wang J.H., Calvet L.E., Chen J., Klemic J.F., Reed M.A. // Appl. Phys. Lett. 1999. Vol. 75. P. 1086-1088. DOI: $10.1063 / 1.124605$

[16] Deal B.E., Grove A.S. // J. App. Phys. 1965. Vol. 36. P. 3770-3778. DOI: $10.1063 / 1.1713945$ 
[17] Grove A.S. Physics and Technology of Semiconductor Device. NY:: Willey, 1967. Ch. 2.

[18] Lagoudas D.C., Ma X., Miller D.A., Allen D.H. // Int. J. Engrg. Sci. 1995. Vol. 33. P. 2327-2343. DOI: 10.1016/0020-7225(95)00073-7

[19] Entchev P.B., Lagoudas D.C., Slattery J.C. // Int. J. Engrg Sci. 2001. Vol. 39. P. 695-714. DOI: $10.1016 / \mathrm{S} 0020-7225(00) 00053-7$

[20] Unnam J., Shenoy R.N., Clark R.K. // Oxidation of Metals. 1986. Vol. 26 (3/4). P. 231-252. 